\title{
KAJI BANDING PENINGKATAN PRODUKSI TERNAK BABI DI PROVINSI BALI MENGGUNAKAN TEKNOLOGI INSEMINASI BUATAN DAN KAWIN ALAM
}

\author{
SUMARDANI, N. L. G., K. BUDAARSA, T. I. PUTRI, DAN A. W. PUGER \\ Fakultas Peternakan Universitas Udayana \\ e-mail: nlg_sumardani@unud.ac.id
}

\begin{abstract}
ABSTRAK
Penelitian ini bertujuan untuk mengetahui perbandingan antara teknologi inseminasi buatan dengan kawin alam dalam peningkatan produksi ternak babi di Provinsi Bali. Data yang digunakan berupa sampel, diambil berdasarkan lokasi, waktu, biaya, dan sumber daya manusia. Teknik pengambilan sampel menggunakan teknik purposive random sampling. Variabel yang diamati meliputi: sistem perkawinan, litter size (LZ), calving rate (CR), dan service per conception (S/C). Hasil yang diperoleh adalah teknologi inseminasi buatan $(51,56 \pm 9,43)$ lebih sering diaplikasikan $(\mathrm{P}>0,05)$ dibandingkan dengan kawin alam $(42,33 \pm 8,88)$. Namun demikian hasil pengawinan dari kedua metode tersebut tidak berbeda nyata $(\mathrm{P}<0,05)$. Berturut-turut hasil dari teknologi IB dan kawin alam pada

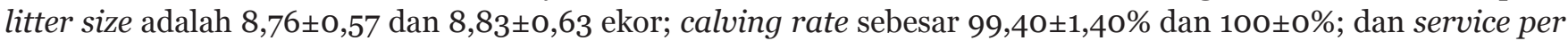
conception 1,00 $\pm 0,02$ dan $1,00 \pm 0$. Disimpulkan bahwa hasil pengawinan secara inseminasi buatan yang meliputi litter size, calving rate dan service per conception, tidak berbeda nyata dengan pengawinan secara alami. Efisiensi pejantan, pengawinan dengan inseminasi buatan lebih efektif dan efisien dibandingkan dengan kawin alam.
\end{abstract}

Kata kunci: inseminasi buatan, litter size, produksi babi, service per conception

\section{THE COMPARISON BETWEEN ARTIFICIAL INSEMINATION TECHNOLOGY AND NATURAL MATING IN INCREASING PIG PRODUCTION}

\begin{abstract}
This study aims to determine the comparison between artificial insemination (AI) technology and natural mating in increasing pig production in Bali Province. The data used in the form of samples, taken based on location, time, cost, and human resources. The sampling method uses purposive random sampling. Variables observed include: mating system, litter size, conception rate and service per conception. From the results of the study, artificial insemination technology $(51.56 \pm 9.43)$ was more frequently applied ( $>0.05)$ compared to natural mating (42.33 \pm 8.88$)$. However, the mating results of the two methods were not significantly different $(\mathrm{P}>0.05)$. Successive results from AI technology and natural mating on litter size were $8.76 \pm 0.57$ and $8.83 \pm 0.63$ heads, CR of $99.40 \pm 1.40 \%$ and $100 \pm 0 \%$, and $\mathrm{S} / \mathrm{C} 1.00 \pm 0.02$ and $1.00 \pm 0$. From this study it can be concluded that the results of artificial insemination mating which includes litter size, conception rate and service per conception, are not significantly different from natural mating. However, in terms of male efficiency, mating with artificial insemination is more effective and efficient compared to natural mating.
\end{abstract}

Keywords: artificial insemination, litter size, pig production, service per conception

\section{PENDAHULUAN}

Ternak babi adalah salah satu ternak penghasil daging yang dapat dikembangkan dalam skala ekspor karena ternak babi memiliki kelebihan antara lain: pertumbuhan yang cepat, jumlah anak per kelahiran yang tinggi, efisiensi terhadap pakan mencapai 70-80\%, dan memiliki kandungan karkas yang tinggi mencapai 65-80\%. Ternak babi mampu memanfaatkan limbah pertanian sebagai bahan pakan untuk meningkatkan kualitas daging yang dihasilkan. Selain itu juga, ternak babi memiliki karakteristik reproduksi yang unik dibandingkan dengan ternak non ruminansia lainnya, karena ternak babi mampu menghasilkan 10-14 ekor per kelahiran, dan memiliki waktu atau lama kebuntingan yang singkat, yaitu rata-rata 114 hari (Sihombing, 2006; Sumardani et al., 2010 ${ }^{\mathrm{a}}$; 2016; 2017; 2018).

Usaha untuk meningkatkan produksi ternak babi, dalam hal ini meningkatkan jumlah populasi, dapat dilakukan dengan meningkatkan efisiensi reproduksi 
melalui aplikasi inseminasi buatan (IB) menggunakan semen cair babi yang berasal dari semen babi pejantan superior, unggul dan terpilih. Jenis babi unggul yang dimaksud adalah babi ras jenis Landrace, Yorkshire dan Duroc, maupun babi ras persilangannya. Unit Pelaksana Teknis Balai Inseminasi Buatan Daerah Provinsi Bali di Baturiti (UPT BIBD) adalah satu-satunya balai inseminasi buatan di Provinsi Bali yang memproduksi semen cair babi unggul, yang nantinya disebarluaskan kepada petani peternak di seluruh Provinsi Bali, bahkan diluar Pulau Bali.

Babi pejantan, unggul secara kualitas, merupakan salah satu syarat penting untuk proses produksi semen cair babi, karena hal ini merupakan standar produksi yang harus dipenuhi dan akan berkaitan erat dengan jumlah induk yang dapat di inseminasi, jumlah produksi semen, dan tingkat fertilitas, sehingga semen cair yang dihasilkan oleh pejantan unggul tersebut harus melewati beberapa tahap evaluasi baik itu evaluasi secara makroskopis maupun mikroskopis, sebelum diproses lebih lanjut sebagai semen cair yang siap untuk disebarluaskan ke masyarakat petani dan peternak.

Masyarakat petani dan peternak di Provinsi Bali, masih ada yang menerapkan perkawinan pada ternak babi secara tradisional yaitu dengan kawin alam, tidak menggunakan teknologi inseminasi buatan. Perkawinan dengan teknologi kawin buatan (inseminasi buatan), maupun dengan kawin alam tentu saja memiliki nilai kelebihan maupun kekurangannya. Oleh karena itu, dalam penelitian ini kami ingin melihat dan membandingkan sejauh mana peranan antara kawin buatan (inseminasi buatan) dan kawin alam dalam meningkatkan produksi ternak babi di Provinsi Bali.

\section{MATERI DAN METODE}

Materi yang digunakan dalam penelitian ini adalah sejumlah semen cair produksi BIBD Provinsi Bali, yang digunakan dalam proses perkawinan dengan teknologi inseminasi buatan. Data diperoleh dari inseminator, wawancara langsung dengan peternak, dan catatan dari BIBD Provinsi Bali. Metode yang digunakan adalah purposive random sampling, berdasarkan lokasi, waktu, biaya, dan tenaga lapangan. Data yang diperoleh berdasarkan inseminator yang bertugas di tiap kabupaten/kota di Provinsi Bali

Variabel yang diamati meliputi: sistem perkawinan alam atau buatan, jumlah anak per kelahiran (litter size), conception rate (CR) dan service per conception (S/C). Data yang diperolah dianalisis deskriptif, dan dianalisis dengan T-test (the two independent sample t-test) (Steel dan Torrie, 1993) untuk mengetahui perbandingan antara kawin alam dengan kawin buatan dalam meningkatkan produksi ternak babi di Provinsi Bali.

\section{HASIL DAN PEMBAHASAN}

Hasil dari 300 sampel ejakulat dari pejantan jenis Landrace di UPT BIBD Provinsi Bali, secara umum adalah baik, secara makroskopis meliputi warna semen putih krem, berbau khas, kisaran pH 6-7, dan konsistensi atau kekentalan adalah cair. Pengamatan secara mikroskopis dapat dilihat dalam Tabel 1.

Tabel 1. Rataan kualitas semen cair babi Landrace di UPT BIBD Provinsi Bali (2018-2019)

\begin{tabular}{lccc}
\hline \multirow{2}{*}{ Variabel } & Ras & \multicolumn{2}{c}{ Kelompok Umur } \\
\cline { 3 - 4 } & & $\mathrm{A}$ & $\mathrm{B}$ \\
\hline Volume semen (ml) & $\mathrm{Ldr}$ & $273,60^{\mathrm{a}} \pm 1,23$ & $107,66^{\mathrm{b}} \pm 1,22$ \\
Motilitas spermatozoa (\%) & $\mathrm{Ldr}$ & $73,86^{\mathrm{a}} \pm 1,18$ & $62,92^{\mathrm{b}} \pm 2,23$ \\
Total produksi semen (tube) & $\mathrm{Ldr}$ & $134,07^{\mathrm{a}} \pm 1,29$ & $30,10^{\mathrm{b}} \pm 0,89$ \\
\hline
\end{tabular}

Keterangan:

1) Ldr: Pejantan Landrace; A: umur 2-4 tahun; B: umur 6-8 tahun

2) Nilai dengan huruf yang berbeda pada baris yang sama menunjukkan berbeda nyata $(P>0.05)$

Produksi semen cair pada ternak babi dapat dipengaruhi oleh beberapa faktor, yaitu: pakan, temperatur dan musim, frekuensi ejakulasi, penyakit, libido, transportasi ternak, umur, dan aktivitas pejantan (Arifiantini dan Tuty, 2012). Rendahnya kualitas pakan dapat menggangu pertumbuhan pejantan, menurunkan jumlah spermatozoa dalam satu kali ejakulasi, dan menurunkan libido. Namun, kualitas pakan yang terlalu tinggi dapat menyebabkan infertilitas. Nuryadi (2013) menyebutkan bahwa kegemukan dan kelebihan pakan dapat menurunkan libido dan aktivitas sexual pada ternak. Oleh karena itu, pejantan perlu diberikan asupan pakan yang sesuai dengan kebutuhannya agar kualitas dan kuantitas semen yang dihasilkan tetap pada grade terbaik.

Implementasi dari program inseminasi buatan pada ternak babi di lapangan, dilaksanakan oleh para inseminator yang terdaftar pada UPT BIBD Provinsi Bali di Baturiti, yang menggunakan semen cair produksi UPT BIBD. Distribusi inseminator yang terlibat dalam penelitian ini, menurut catatan pada UPT BIBD Provinsi Bali, adalah di Kabupaten Badung sebanyak tiga orang, Tabanan empat orang, Gianyar dua orang, Bangli satu orang, Klungkung satu orang, Karangasem satu orang, Buleleng satu orang, Jembrana satu orang, dan Kota Denpasar sebanyak dua orang. Peningkatan produksi ternak babi melalui usaha peningkatan populasi ternak babi di masyarakat dapat dilakukan dengan perkawinan alam maupun perkawinan melalui inseminasi buatan, seperti pada Gambar 1 (Sumardani et al., 2010 ${ }^{\mathrm{b}}$; 2015).

Dari hasil penelitian (Tabel 2) menunjukan bahwa, rataan perkawinan secara alami adalah sebesar 42,33 kali dan secara inseminasi buatan sebesar 51,56 kali, jumlah rataan anak per kelahiran adalah 8 ekor, 


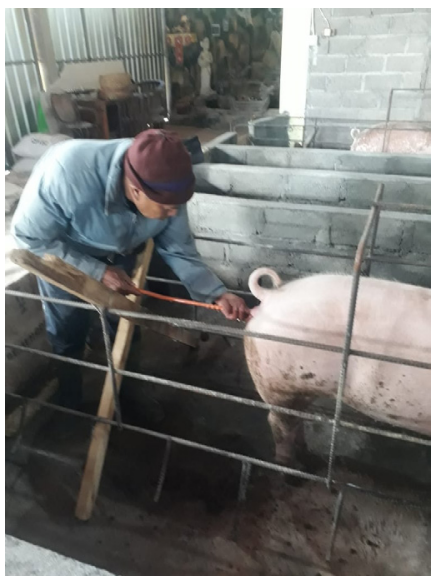

(a)

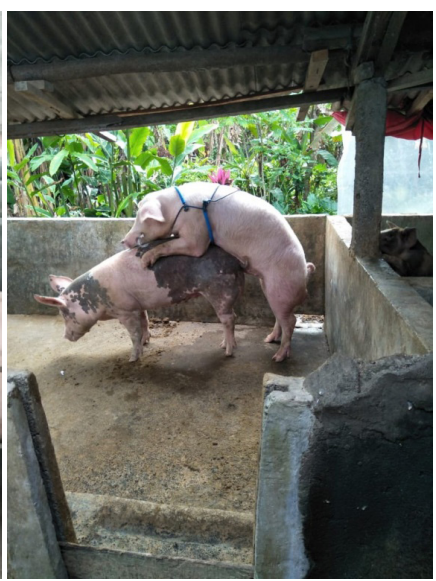

(b)
Gambar 1. Ternak babi Landrace yang dikawinkan melalui teknik Inseminasi Buatan (a) dan teknik perkawinan alam (b) (dok. Sumardani, 2019).

$\mathrm{S} / \mathrm{C}$ rata-rata adalah 1 , conseption rate $100 \%$ untuk perkawinan secara alami, dan 99,4\% untuk perkawinan melalui inseminasi buatan. Secara statistika, hal ini tidak berbeda nyata. Perkawinan secara alami maupun secara inseminasi buatan, sama-sama menghasilkan nilai yang baik.

Implementasi sistem perkawinan ternak di lapangan dipengaruhi oleh situasi dan kondisi dari peternak dan ternak itu sendiri. Namun demikian, dalam peningkatan produksi ternak babi secara efektif dan efisien dapat dilakukan dengan menerapkan teknologi inseminasi buatan dalam perkawinan ternak. Dari hasil penelitian (Tabel 2) terlihat bahwa jumlah pengawinan dengan kawin alam sebanyak 42,33 $\pm 8,88$ kali, dan dengan IB sebanyak 51,56 \pm 9,43 kali. Hal ini menunjukkan bahwa dengan teknologi IB maka penggunaan pejantan menjadi lebih efektif dan efisien. Beberapa keuntungan yang diperolah dari penerapan IB di peternak yaitu: (1) efisensi penggunaan pejantan unggul; (2) pencegahan penyakit menular; (3) mencegah kawin sedarah (inbreeding); (4) mempermudah penyebaran bibit-bibit unggul; (5) dapat mengatur jarak kelahiran ternak dan memperpendek calving interval; serta (6) mengurangi kawin berulang pada induk.

Mempertahankan tingkatan fertilitas yang tinggi adalah dasar dan tujuan setiap program peternakan. Makin banyak ternak betina yang kawin berulang (repeat breeders) akan sangat merugikan baik bagi pelaksana inseminasi bauatan maupun bagi peternak (Toelihere, 1993; Feradis, 2010). Walaupun keunggulan genetik pejantan yang ditonjolkan dalam suatu program inseminasi buatan, namun kesediaan peternak menerima pelayanan inseminasi terutama didasarkan pada pertimbangan-pertimbangan ekonomik. Konsepsi yang tertunda dapat menyebabkan kerugian finansial bagi peternak. Peternak yang mengalami hasil-hasil konsepsi yang rendah dengan pelaksanaan inseminasi buatan pada ternaknya akan cenderung untuk kembali menggunakan perkawinan alam.

Dari hasil pengamatan diketahui bahwa angka konsepsi $100 \%$ untuk perkawinan secara alami, dan 99,4\% untuk perkawinan melalui inseminasi buatan. Angka konsepsi (conception rate) ditentukan berdasarkan hasil diagnosa kebuntingan pada inseminasi pertama. Angka konsepsi ini ditentukan oleh tiga faktor yaitu kesuburan pejantan, kesuburan betina, dan teknik inseminasi. Teknik inseminasi yang baik, dapat mempertahankan nilai dari angka konsepsi. Dalam hal ini, tenaga inseminator harus memiliki pengetahuan dan keterampilan dalam teknik inseminasi buatan pada ternak babi, termasuk juga pengetahuan tentang ilmu reproduksi ternak babi baik jantan maupun betina. Tingkat pengetahuan dan pengalaman inseminator di lapangan, juga memegang peranan yang sangat penting dalam pelaksanaan inseminasi buatan, karena hal ini akan berkaitan erat dengan tingkat keberhasilan dalam inseminasi. Waktu yang tepat untuk pelaksanaan inseminasi pada induk babi yang sedang estrus, yaitu hari kedua setelah

Tabel 2. Kaji banding peningkatan produksi ternak babi melalui teknologi inseminasi buatan dan kawin alam

\begin{tabular}{|c|c|c|c|c|c|c|c|c|}
\hline \multirow{2}{*}{$\begin{array}{c}\text { Kabupaten/ } \\
\text { Kota }\end{array}$} & \multicolumn{2}{|c|}{ Jumlah Pengawinan } & \multicolumn{2}{|c|}{ LZ (ekor) } & \multicolumn{2}{|c|}{ CR (\%) } & \multicolumn{2}{|c|}{$\mathrm{S} / \mathrm{C}$} \\
\hline & $\mathrm{KA}$ & KB & $\mathrm{KA}$ & KB & $\mathrm{KA}$ & KB & $\mathrm{KA}$ & KB \\
\hline Badung & 87 & 96 & $9,54 \pm 0,75$ & $9,43 \pm 0,52$ & 100 & 95,83 & 1,00 & 1,04 \\
\hline Bangli & 20 & 16 & $8,95 \pm 1,01$ & $9,25 \pm 1,24$ & 100 & 100 & 1,00 & 1,00 \\
\hline Buleleng & 28 & 16 & $9,25 \pm 1,55$ & $8,44 \pm 0,13$ & 100 & 100 & 1,00 & 1,00 \\
\hline Jembrana & 15 & 16 & $8,70 \pm 1,01$ & $8,06 \pm 0,52$ & 100 & 100 & 1,00 & 1,00 \\
\hline Karangasem & 20 & 16 & $8,60 \pm 0,49$ & $7,81 \pm 0,52$ & 100 & 100 & 1,00 & 1,00 \\
\hline Tabanan & 108 & 160 & $9,50 \pm 0,51$ & $9,14 \pm 0,93$ & 100 & 98,75 & 1,00 & 1,03 \\
\hline Gianyar & 68 & 64 & $9,12 \pm 0,54$ & $8,89 \pm 0,61$ & 100 & 100 & 1,00 & 1,00 \\
\hline Klungkung & 25 & 16 & $8,16 \pm 1,05$ & $8,63 \pm 0,32$ & 100 & 100 & 1,00 & 1,00 \\
\hline Denpasar & 10 & 64 & $7,63 \pm 1,00$ & $9,22 \pm 0,55$ & 100 & 100 & 1,00 & 1,00 \\
\hline Rataan & $42,33 \pm 8,88$ & $51,56 \pm 9,43$ & $8,83 \pm 0,63$ & $8,76 \pm 0,57$ & 100,0 & $99,40 \pm 1,40$ & 1,00 & $1,01 \pm 0,02$ \\
\hline
\end{tabular}

Keterangan:

KA (kawin alam); KB (kawin buatan atau IB); LZ (litter size); CR (conception rate); S/C (service per conception). 
tanda estrus pertama muncul; dosis semen cair yang sesuai dengan kebutuhan induk, berkisar 70-80 ml; dan teknik inseminasi buatan yang baik dan benar dari inseminator; akan memberikan persentase dan peluang keberhasilan kebuntingan pada induk semakin tinggi.

\section{SIMPULAN}

Dari hasil penelitian ini dapat disimpulkan bahwa tidak ada perbedaan nyata antara sistem perkawinan melalui inseminasi buatan maupun secara alami, dalam upaya meningkatkan jumlah anak per kelahiran (litter size), conception rate, dan service per conception, tetapi dengan teknologi IB maka penggunaan pejantan menjadi lebih efektif dan efisien.

\section{DAFTAR PUSTAKA}

Arifiantini, R.I dan Tuty L.Y. 2012. Teknik Koleksi dan Evaluasi Semen pada Hewan. Penerbit: IPB Press, Bogor.

Feradis. 2010. Bioteknologi Reproduksi Pada Ternak. Penerbit: Alfabeta, Bandung.

Nuryadi. 2013. Ilmu Reproduksi Ternak. Penerbit: UB Press, Malang.

Sihombing DTH. 2006. Ilmu Ternak Babi. Penerbit: Gadjah Mada University Press, Yogyakarta.

Steel, R.G.D. dan J.H. Torrie. 1980. Principle and Procedures of Statistics. McGraw-Hill Inc. New York. Diterjemahkan oleh: B. Sumantrini. 1993. Prinsip dan Prosedur Statistika. Penerbit: PT Gramedia Pustaka Utama, Jakarta.

Sumardani, N. L. G, I. P. Arnaya, dan I. P. Gede Bawa. 2010a. Application of artificial insemination to increase litter zise on pig. Procedings: $2^{\text {nd }}$ International Conferences on Biosciences and Biotechno- logy: Pave the way to a better live. Bali, 23-24 September 2010. ISBN: 978-602-9042-11-5. Halaman: PA.41-PA.43

Sumardani, N. L. G, N. M. Artiningsih, dan I. W. Suberata. 2010b. Peningkatan jumlah kelahiran anak babi melalui teknologi inseminasi buatan di Desa Takmung Klungkung. Jurnal Udayana Mengabdi. Vol. 9 No. 1 Tahun 2010. P: 36-39. https://ojs.unud.ac.id/index. php/jum/article/view/1960/1230

Sumardani, N. L. G, I. G. A. Arta Putra, I. W. Suberata, I. G. Suranjaya, D. K. Harya Putra, dan W. S. Yupardhi. 2015. Teknik dan manajemen produksi bibit babi di Banjar Dauh Uma, Desa Pengotan, Kabupaten Bangli. Jurnal Udayana Mengabdi. Vol. 14 No. 1 Tahun 2015. P: 24-27. https://ojs.unud.ac.id/ index.php/jum/article/view/13207/8886

Sumardani, N. L. G, dan I. N. Ardika. 2016. Populasi dan performa reproduksi babi bali betina di Kabupaten Karangasem sebagai plasma nutfah asli bali. Majalah Ilmiah Peternakan. Vol. 19 No. 3 Tahun 2016. P: 105-109. https://ojs.unud.ac.id/index.php/mip/ article/view/25305/16485

Sumardani, N. L. G, I. W. Suberata, N. M. A. Rasna, dan I. N. Ardika. 2017. Performa reproduksi babi bali jantan di Provinsi Bali sebagai plasma nutfah asli bali. Majalah Ilmiah Peternakan. Vol. 20 No. 2 Tahun 2017. P: 73-78. https://ojs.unud.ac.id/index. $\mathrm{php} / \mathrm{mip} /$ article/view/32221/19432

Sumardani N. L. G, I. W. Suberata, N. M. Artiningsih, dan K. Budaarsa. 2018. Kajian aktivitas ovarium babi Landrace dan babi bali hasil pemotongan di rumah potong hewan tradisional. Majalah Ilmiah Peternakan. Vol. 21 No. 2 Tahun 2018. P: 81-86. https://ojs.unud.ac.id/index.php/mip/article/ view/41432/25226

Toelihere, M. R. 1993. Inseminasi Buatan Pada Ternak. Penerbit: Angkasa, Bandung. 